\title{
The diffusion of medical technology: free enterprise and regulatory models in the USA
}

\author{
A Everette James, Seymour Perry, Susan E Warner, John E Chapman, Richard M Zaner
} Vanderbilt University, Nashville, Tennessee and Georgetown University, Washington DC, USA

\section{Authors' abstract}

The diffusion of technology in the US has taken place in an environment of both regulation and free enterprise. Each has been subject to manipulation by doctors and medical administrators that has fostered unprecedented ethical dilemmas and legal challenges. Understanding these developments and historical precedents may allow a more rational diffusion policy for medical technology in the future.

The diffusion of costly and sophisticated medical technology poses a formidable issue for those entrusted with the formation of health care policy. Efforts to stem the rising cost of health care have often been directed at those areas of the delivery system with high unit costs, particularly at instruments for diagnostic medical imaging. Examples are computed tomographic (CT) scanners (1), angiographic suites, machines for positron emission tomography (2), and now devices for magnetic resonance imaging (MRI). Policies relating to health care in the United States are both formulated and administered at the state level, and the states have a superior mandate to federal legislation (3). Thus, one has the opportunity to observe two divergent philosophies of health care policy, the free enterprise (market-place) model on the one hand and regulation on the other. Each system has inherent advantages and limitations, and poses different ethical issues.

Medicine in the United States has historically been exempt from much of the regulatory legislation and scrutiny applied to the financial world. Much of this tacit and de facto exemption went under the philosophical rubric of the 'learned professions' exclusion. Medicine, law and other professions were judged upon their benefit to the public welfare. However, in 1975, in the landmark case of Goldfarb $v$ Virginia State Bar, the Supreme Court recognised that

\section{Key words}

Medical technology diffusion; health care costs; exclusive hospital privileges; radiology; certificate of need (CON); computed tomographic (CT) scanners; magnetic resonance imaging (MRI); free enterprise (market-place) model; tying arrangement; regulatory process. professions might have a significant business aspect in their conduct and that those activities so characterised should fall under the regulation of the Sherman Antitrust Act of 1890 and all of the subsequent acts applicable to business enterprise (4).

The magnitude of the business of medicine was found to represent over 10 per cent of the gross national product and was estimated at that time (1975) to be greater than two hundred billion dollars. The Federal Trade Commission, a government agency mandated to regulate interstate commerce, began investigating many of the commercial relationships in medicine which had been operating without external scrutiny and which had historically been accorded the privilege of self-regulation.

Concomitant with these changes in federal policies was one of the singular medical developments of the 20th century, the introduction in the mid-1970s of $x$ ray CT scanners (5). Developed in England by EMI, these instruments radically changed the diagnostic investigation process for many conditions. The public and the medical profession became so enamoured with these marvellous new devices of diagnostic inquiry that the demand by patients and doctors appeared unlimited. However, the unit costs exceeded a million dollars (US).

In an attempt to bring order to potential chaos in the diffusion of these 'CAT' scanners, certificates of need (CON) legislation was enacted by the US government. This required potential acquirers of medical facilities or technology above a certain monetary value to demonstrate both the clinical need for this capability and their qualifications for being accorded this responsibility of ownership. These $\mathrm{CON}$ requirements were administered by state agencies and therefore were not uniform in their regulatory effect. Additionally, they did not apply to outpatient facilities - meaning that even when the policy-makers imposed regulation, it affected only one segment of the health care system. Doctors and entrepreneurs could purchase these units with impunity, as long as they were outside a hospital facility, and they were willing to assume the financial risk.

Another significant development of the 1970s that continues to have great influence on the character of medical care in the US has been the increased difficulty 
that doctors have in acquiring hospital privileges $(6,7)$. Several legal decisions, including the landmark case of Darling $v$ Charleston Community Hospital, made it clear that hospitals were ultimately liable for the quality of practice provided by their staff. Granting of hospital privileges became a much more regulated and restrictive process, and the number of doctors excluded from these institutions that had installed the most sophisticated and costly medical imaging technology increased dramatically from that time. This created a new type of demand for access. In addition to patient demand, there was now doctor demand for all the institutions with whom they were associated to acquire the diagnostic capabilities afforded by CT scanners and other expensive instruments.

While many hospitals expended considerable resources in an attempt to meet these demands, there were inherent risks. Institutions incurred substantial debts for equipment whose efficacy had yet to be fully established, and whose technological half-life was unknown. The financial schemes employed to acquire and amortise these units were varied and sometimes incompletely understood by doctors and hospital administrators. Some institutions made financial assumptions regarding compensation that were so favourable as almost to ensure profitability. These complexities may have initially acted as a barrier to diffusion of this technology, but, if so, it was incomplete and short-lived. Regulation did act, however, to make institutional acquisition of this instrumentation geographically non-homogeneous, creating a medical technological circumstance of 'haves and have-nots' (8).

The number of legal challenges by doctors to hospital privilege denial has also increased dramatically. Doctors now believe that in order to maintain professional and fiscal viability they and their patients must have access to this technology. This means that doctors must secure staff privileges at those facilities where these devices have been approved by the CON agency and are in clinical use. Additionally, the securing of exclusive privileges by certain specialty groups for both performance and interpretation of these technological procedures by contract has resulted in many legal challenges $(9,10)$. Some institutions had to gain approval for the acquisition of these devices in order to qualify for compensation from third party payers for those procedures performed on these machines.

While this form of regulation did indeed limit some unstructured diffusion of the x-ray CT scanners, it did so in a very erratic manner and only in the institutional setting. 'Fugitive' CT scanners were acquired in outpatient facilities and private offices - often competing unfairly with institutions because a CON was not needed and the lengthy and rigorous process of receiving approval could be avoided.

Additionally, doctors often found themselves in a novel ethical dilemma. In order to finance the acquisition of these $\mathrm{x}$-ray CT devices and, later, MRI scanners for private outpatient use, partnerships were formed under the appellation of 'imaging centres'. Often, a group of doctors (the imaging team) would enter into a financial arrangement whereby they would become the general partners in this economic venture and their referring doctors would become the limited partners. This would be a business with definite economic implications for the doctors, who would have a vested financial interest in the economic viability of their commercial enterprise, the imaging centre. The property was usually acquired and the installation financed by a loan from commercial financial agencies, and the technology was leased from the manufacturer or from a lending agency specialising in the financing of such equipment. General partners were at risk for the general financial welfare of the venture, whereas the limited partners were liable only for their initial investment.

The ethical considerations are that access of their patients to this necessary resource is secured, but the doctors are financially involved in circumstances for which there is no historical precedent. The need to utilise, and the temptation to over-utilise, the facility to assure its economic welfare are readily apparent. Additionally, doctors who have no financial interest in the imaging centre may find that their patients' access is limited by the preferential treatment of the patients of the partners in the enterprise. Many ethicists and policy-makers in the US have reasoned that this only appears to be free enterprise. In fact the fiduciary capacity of the doctors allows them so to determine the acquisition and use of the instrumentation that it represents a tacit monopoly, and this is more of an adaptation to intended regulation than the ebb and flow of market-place activity. This has been viewed as a 'tying arrangement', whereby free choice by the patient is precluded by the financial arrangements of his or her doctor.

The series of activities described above were the focus of much public attention in the US for approximately four to five years in the late 1970s due to the phenomenon of $\mathrm{x}$-ray computed tomography, although implications for other facilities such as angiographic suites, radiation oncology treatment centres, and digital radiology laboratories (11) were also significantly affected. By the early 1980s, however, the use of CT scanners had become widespread and they were no longer an important health policy issue. $\mathrm{CON}$ agencies became more liberal in their requirements, and in some states were abandoned, as their operational costs were not appropriated from public funds, and doctor and patient expectations for these 'wonder devices' became more realistic as clinical experiences became widely reported. These clinical analyses provided some medical guidelines for the rational distribution of this technology. The ethical choices then assumed a more traditional medical posture, and economic consideration reverted to the traditional 'patient welfare' character. 
However, the previously described phenomenon was to arise again in the early to mid-1980s with the clinical introduction of MRI (12). Although the process of nuclear magnetic resonance (NMR) as an analytic technique for biological materials had been independently described by Block and Purcell in the 1940s (for which they received the Nobel Prize in 1952), the utilisation of this methodology to create images of nuclei in the human body only became a reality in the late 1970s. By the early 1980s, several famous institutions in England, Scotland and the United States were exploring clinical uses of these devices to diagnose fundamental chemical and physiological changes reflecting both health and disease (13). The public enthusiasm for MRI was equal to if not greater than that engendered by the CT scanner, and the demand for these devices from doctors and the informed public was commensurate. Because radio-frequency waves were employed as the energy utilised to create the image signal rather than ionising radiation, the biological implications for MRI were profoundly different from, and compared very favourably with, devices using ionising radiation. In theory, the potential biological burden with MRI was felt to be much less than with computed tomographic or conventional radiographic or radionuclide diagnostic studies. However, experimental data and clinical experience was lacking in regard to the effects of this energy form on the human body. Thus, there were inherent risks in proliferation and diffusion of these revolutionary instruments.

In addition to the $\mathrm{CON}$ process, it was decided that prior to approved clinical introduction, leading to reimbursement by third party payers, this form of diagnostic procedure (MRI) had first to be evaluated by the Federal Drug Administration (FDA), the Office of Technology Assessment (OTA) and the Health Care Financing Agency (HCFA). Manufacturers were to submit to the FDA their clinical prototype experience at different magnet strengths (for example: 0.5 tesla and 1.5 tesla) and for different anatomical areas (brain, abdomen, etc) in order to get agency approval. Third party payers could elect to compensate doctors and institutions for the studies, depending upon approval from the regulatory agencies. Many policy-makers felt that this form of multi-agency regulation would obviate many of the economic incentives and might assist in avoiding the ethical dilemmas to which doctors had succumbed with computed tomography.

While this regulatory process had inherent difficulties and was rigorous in its administration, the perceived demand for MRI by patients and doctors was so great that instrument manufacturers and leading medical institutions engaged in a monumental collaborative effort to meet these requirements in order to acquire these devices. In financial terms, these facilities cost several million dollars per unit to purchase and were extremely difficult to place on medical sites due to the necessity of radio-frequency shielding for the instrument itself (14). This environment created some momentary concern among institutions, as they were reluctant to purchase such expensive devices if the possibility existed that they would not subsequently be reimbursed for the studies performed. On the other hand, doctor and public fascination with the technology and potential capability of MRI reached an unprecedented level and the lay literature and public awareness of the supposed virtues of this technique made the acquisition by medical facilities extremely compelling. Many health care facilities entered willingly into the necessary process to meet the regulations. The imaging centre scenario was revisited with even greater intensity than with computed tomography.

Soon the rapid diffusion of MRI devices became the concern of health policy groups (15). Medicine and doctors entered again into a number of financial arrangements that posed serious ethical questions. Despite the efforts of doctors to remain unbiased and not to refer their patients for studies in facilities that they owned, there obviously remained a strong financial incentive to do so. Competition for referrals began to involve marketing techniques that were often so aggressive they also posed ethical dilemmas for doctors.

The health care analysts and policy-makers in the US who oppose regulatory schemes as a nationap strategy are in favour of the traditional free-enterprise system and the market-place model (16). They believê that the health-care delivery-system, albeit quite complex, is a large and powerful business and should operate according to the principles of supply and demand. These proponents believe that the accommodations and realities of the market-place will best serve the consumer public and that regulation of health care will create inequities in this system that are both false and unfair. Such fundamental virtues as selfdetermination, free enterprise and consumer participation are cited as inherent virtues by the champions of this health-policy model.

To some extent, the business model of free enterprise has continued to operate in the medical technology area despite attempts at regulation. The CON process, as noted, could be avoided by placing the instrumentation in an outpatient facility or in a private office. In the past decade, the 'medical imaging centre' has been a national phenomenon (17). These centres proliferated due to the availability of venture capital, favourable tax laws on investments, and awareness of both doctors and non-doctors of the potential profits from these facilities. The scheme whereby referring doctors would become limited partners with the largest investors (who were often non-doctors) as the general partners is a new development for the medical field - the propriety of which is questionable. Participation in such an ownership arrangement of a health-care facility by doctors creates, at best, an ethical dilemma; in the United States, it introduces certain legal issues of antitrust as well (18). The arrangements have been 
challenged in the courts as: 'tying arrangements', whereby the patients' choices are limited; marketplace exclusion where non-owner doctors and their patients are denied access; and monopolisation, in which other regulated health-care facilities in the same area cannot acquire an MRI system because the clinical need has been precluded by the presence of an imaging centre (19).

In order to increase the patient population which these 'centres' may serve, the instrumentation is sometimes housed in mobile vans that can be moved from site to site according to an elaborately prearranged schedule. 'Mobile' imaging centres not only avoid much of the regulatory process but markedly increase the numbers of hospitals that can afford this capability at least on a part-time basis. Quality control in the very broadest sense has become a major issue and an area of serious disagreement - not only between the practising doctors and their investors but among referring doctors and those providing the interpretative service (10). Medical educators have become rightly concerned that both patients and the latest in medical technology will be so displaced into remote outpatient facilities in the private sector that this will no longer be an available resource for medical student and registrar training. Since these are commercial operations, one might argue that they have no responsibility for training and teaching. Additionally, if patient access is only afforded by the mobile unit, cannot quality control be relaxed in order to assure availability? One might conclude that service to a large patient population, even if it is not ideal, may be preferable to service for only a few. We would hasten to add that precious little data are available to analyse whether inpatient MRI achieves better quality of medical care than MRI performed in an outpatient setting.

Except for economic realities, the diffusion of these imaging centres often seems to be almost unregulated; even in the regulated sector, many of the constraints can be circumvented. The cost of medical care in the US by the mid-1980s was above three hundred billion dollars, and there were frequent predictions that, given existing trends, the Medicare and Medicaid trust funds would be bankrupt by the 1990s. Doctors were identified as the major decision-makers in the healthcare industry; therefore, in order for any programme to be effective in reducing this rising cost, doctors' habits of utilisation of these capabilities would need to be changed. This posed much more of an economic decision than an ethical one. Measures were enacted to alter doctor behaviour, utilising financial incentives.

Policy-makers, after evaluation of the American reimbursement system, formulated a prospective payment scheme whereby an amount of funds would be allocated to a certain proposed diagnosis. Should this amount be exceeded, additional funds would either be requested by the institution or the costs would have to be borne by the health-care facility $(20,21)$. The implications of this scheme for large expenditures to purchase capital equipment are obvious. This system, known as diagnosis-related groups (DRGs), has not been operational for a sufficient period to assess its long-term effect upon medical technology diffusion. We would predict that institutions might be reluctant to acquire expensive medical imaging-devices unless they are assured that reimbursement will be sufficient to service the associated debt. Therefore, DRGs should act to limit medical technology diffusion to some degree (22). This methodology also places doctors in a 'gatekeeper' role by virtue of them having to approve diagnostic tests for their patients. This role is worrying for many doctors because they feel they are 'rationing' care for their patients.

More recently, policy-makers have criticised the medical reimbursement system in the US as favouring technological procedures and disproportionately increasing the incomes of the specialists engaged in these practices. The so-called 'cognitive' disciplines such as primary care, paediatrics, general internal medicine and psychiatry have been disadvantaged by the current medical compensation themes in the US. A system of assignment of values for each medical activity has been proposed, and a set of relative value scales (RVS) for all types of medical encounters is being developed. These resource-based relative value scales are to be incorporated into the federally funded medical compensation system. One would expect that private insurance companies and other third party payers would adjust their payment schedules accordingly. If compensation for procedures involving these expensive devices appears threatened, the resistance to acquiring this instrumentation will certainly increase.

An ethical dilemma for doctors is whether they believe they should forego a procedure for their patients if it will deplete the institutional resources (DRG) or even their personal income (RVS). Doctors in the US agree that health care costs have significant implications for the economy in general and that changing the pattern of their practices from high technology to that of more traditional medical inquiry would decrease costs. However, with patient welfare as the primary criterion, should not technology be widely distributed and free access provided to everyone? The financial implications in terms of human value are difficult to quantify. Patients given free choice have traditionally selected the most technological and, thus, the most expensive form of health care. Patients want access to this type of medicine, but would they if they had the necessary data to understand the financial implications?

In summary, the diffusion of technology in the US has taken place in an environment characterised by regulation on one hand and the free-enterprise or market-place model on the other. Each has been subject to certain manipulation by doctors and medical administrators which has fostered unprecedented ethical dilemmas and legal challenges. Understanding 
these developments and historical precedents will, it may be hoped, allow a more rational diffusion policy for medical technology in the future. What is apparent is that if a regulatory model is chosen, the entire healthcare system should be regulated. If doctors are to implement a regulatory system, they must be an identifiable and significant part of the formulation process. Regulation is only effective if there are penalties; the penalties should be so imposed, however, that patient welfare is not compromised by the system. The free-enterprise system is difficult to apply to medicine because of the fiduciary capacity of the health-care providers and the lack of an effective voice for the consumer, the patient. The most likely posture for future health-care policy in the US will be regulation through economics, which as a secondary effect will limit the free diffusion of costly technology.

\section{Acknowledgements}

We are grateful for the advice of colleagues Vice Chancellor Roscoe $\mathbf{R}$ Robinson of Vanderbilt University Medical Center; Frank Sloan, Vanderbilt Institute for Public Policy Studies; Jim Blumstein, Vanderbilt University School of Law; Terry Calvani, Federal Trade Commission; A Everette James, III, MBA/JD; Jeannette James, JD; Barbara McNeill, Harvard Medical School; Earl Steinberg, Johns Hopkins Medical Institution, and Tom Greeson of the American College of Radiology. The editorial office of the Division of Radiological Sciences (Tom Ebers, editor) and the Center for Medical Imaging Research were utilised.

A Everette $\mathcal{F a m e s} \mathcal{F r}, S c M, \mathcal{F} D, M D$ is Senior Research Associate, Vanderbilt Institute for Public Policy Studies; Lecturer in Legal Medicine, Department of Medical Administration; and Professor and Chairman, Department of Radiology and Radiological Sciences, Vanderbilt University School of Medicine. Seymour Perry $M D$ is Professor, Department of Community and Family Medicine, Georgetown University School of Medicine; and Senior Fellow, Institute for Health Policy Analysis, Georgetown University. Susan E Warner MSSW, MDiv is Graduate Assistant, Center for Clinical and Research Ethics, Vanderbilt University School of Medicine. Fohn E Chapman MD is Dean of the School of Medicine and Professor of Medical Administration and Chairman of the Division, Vanderbilt University School of Medicine. Richard M Zaner PhD is Ann Geddes Stahlman Professor of Medical Ethics and Director of the Center for Clinical and Research Ethics, Vanderbilt University School of Medicine; and Professor of Medical Ethics, Vanderbilt University Divinity School.

Please address all correspondence to Dr James, Department of Radiology and Radiological Sciences, Vanderbilt University Medical Center, Nashville, TN 37232-2675, USA. Telephone: (615) 322-3357. Fax: (615) 322-3764.

\section{References}

(1) James A E Jr, Anderson J H, Higgins C B, eds. Digital image processing in radiology. Baltimore: Williams and Wilkins, 1984.

(2) Kessler R M, Partain C L, Price R R, James A E Jr. Positron emission tomography: prospects for clinical utility. Investigative radiology 1987; 22: 529-537.

(3) James A E Jr, ed. Medical/legal issues for radiologists. Chicago: Precept Press, 1987.

(4) James A E Jr, Curran W J, Pendergrass H P, Chapman $\mathrm{J}$ E. Academic radiology, turf conflict and antitrust laws. Investigative radiology 1990; 25: 200-202.

(5) Coulam C M, Erickson J J, Rollo F D, James A E Jr, eds. The physical basis of medical imaging. New York: Appleton-Century-Crofts, 1981.

(6) James A E Jr, Sloan F, Blumstein J, Winfield A C, Pendergrass H P. Certificate-of-need in an antitrust context. Fournal of health politics, policy and law 1983; 8: 314-319.

(7) James A E Jr, Winfield A C, Rollo F D, et al. An analysis of the combined effects of certificate of need legislation (CON) and changes in the granting of hospital privileges. Radiology 1982; 145: 229-231

(8) James A E Jr, Sloan F A, Pendergrass H P, et al. Hospital cost regulation: some cumulative effects from certificate of need and diagnostic related groups. Noninvasive medical imaging 1984; 1: 259-263.

(9) James A E Jr, Sloan F A, Hamilton R, et al. Antitrust aspects of exclusive contracts in medical imaging Radiology 1985; 156: 237-241.

(10) James A E Jr, Pendergrass H P, Robinson R, Hamiltor R J, Rollo F D, Hollowell E. Exclusive physiciaw contracts in hospitals: precedent cases for radiologic practice. Administrative radiology 1987; 6: 14-17.

(11) James A E Jr, Partain C L, Pendergrass H P. Certain legal considerations of digital radiological imaging. In: Price R R, Rollo F D, Monahan W G, James A E Jr, eds Digital radiography: a focus on clinical utility. New York: Grune and Stratton, 1982: 121-145.

(12) James A E Jr, Gore J, James A E III, et al. Legal aspects of MRI. In: Partain C L, Price R R, Patton J A, Kulkarni M V, James A E Jr, eds. Magnetic resonance imaging (2nd ed). Philadelphia: W B Saunders Company, 1988: 913-939.

(13) James A E Jr, Partain C L, Patton J A, et al. Current status of magnetic resonance imaging. Southern medical journal 1985; 78: 580-597.

(14) Price R R, Stephens W H, Partain C L. NMR physical principles. See reference (12): 971-986.

(15) International symposium: The impact of new imaging technology on health care, research, and teaching: 1 . current status. American journal of roentgenology 1983; 141: 1335-1350.

(16) James A E Jr, Price R R, Sloan F, Zaner R, Chapman J. Certain social considerations in abandoning high technology medical imaging. Health matrix $1987 ; 5$ : 3134.

(17) James A E Jr, Chapman J E, Carroll F, et al. Ethical choices in high technology medicine: current dilemmas in diagnostic imaging. Health care instrumentation 1986; 1: 158-167.

(18) James A E Jr, Partain C L, Hamilton R J, et al. A critique of the concept of MRI centers. Magnetic resonance imaging 1987; 5: 71-75.

(19) James A E Jr, Linton O, James A E III, et al. Some legal రृ issues of turf: relation to magnetic resonance. Magnetic resonance imaging 1990; 8: 1-3. 
(20) James A E Jr. Intrusion of regulatory process to change the face of radiology. Diagnostic imaging 1984; Feb: 4546.

(21) James A E Jr, Greeson T, Price R R, et al. Legal and ethical choices in a technologic discipline: imaging centers, DRGs, and the radiologist. Investigative radiology 1986; 21: 746-751.

(22) James A E Jr, Greeson T, Price R R, et al. Legal and ethical issues in a technologic discipline: new times, new choices. Investigative radiology 1986; 21: 673-677.

\section{News and notes \\ Rationing and the Technologic Future}

An international conference, entitled Rationing and the Technologic Future, will be held on October 28th and 29th this year at Long Beach, California.

The conference will explore the experience of healthcare rationing around the world and how each of the US constituencies involved in paying for and/ or providing healthcare deal with making rationing decisions.

The conference sponsors are the FHP Foundation and the International Society of Technology Assessment in Health Care.

For further information please contact: Sandra Lund Gavin, Executive Director, FHP Foundation. Fax: 213 495-0317; telephone: 213 590-8655; address: 401 Ocean Boulevard, \#206, Long Beach, CA USA 90802. 